scholars, a distinguished artist, and numbers of persons of more than average culture; yet there appears to be no correspondence between the mind and the length of the index finger.

R. A. N.

\section{Extraordinary Tides}

IN Iast week's "Notes" you say, speaking of the unprecedentedily high tide of the 15 th inst., that "no one seems to have expected an unusual tide." Allow me to state, sir, that in the Spectator of Nov. 7 th, 1874 , I predicted this extraordinary tide. As a matter of fact, the tide was higher than that of March 1874 , through the unusually swollen state of the river by floods and the N.W. gale.

No extraordinary tide can occur this side of March 1878 .

4, Buccleuch Place, Dulwich

B. G. JENKINS

\section{Further Linkage Work}

IN the interesting communication to NATURE, vol, xii. pp. 214-216, Prof. Sylvester gives account of the Hart and the Sylvester-Kempe "linkages." Of four points, three have work assigned. Problem: To employ the nondescript point.

First.-The Hart linkage yields the Cissoid, exactly as that curve is defined. Thus, with $p$ circling, $q$ resting, and $s$ tracing straight line ; $r$ traces cissoid. Second. - The Sylvester-Kempe linkage yields the Hyperbola, in that curve's simplest vector form. Thus, with $r$ opposite, to $p$ resting, and $p q, p s$ in constant directions ; $r$ traces the hyperbola whose assymptotes are these directions.

Burntisland, N.B.

\section{A Criminal Dog:}

I was so much pleased with the anecdote in Nature (vol. xiii. p. 36) of the criminal dog who buried the cat he had murdered, that I told my wife; but I did not mention the breed of the dog.

She said, "Was it not a retriever? becanse they always bury their food, so that it may become high." I could but answer that it was a retriever, and added that $I$ was afraid she had hit upon the real reason for the act.

General Post Office, Nov, I2

\section{OUR ASTRONOMTCAL COLUMN}

The Binary Star 44 Bootis.-In No. 2,064 of the Astronomische Nachrichten, Dr. Doberck, of Markree Observatory, has given an orbit of this binary, and a comparison with measures to the present year. The elements are--

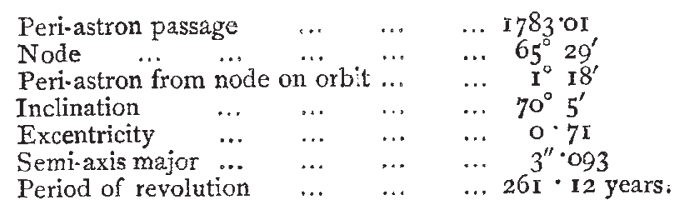

Dr. Doberck makes no reference to Sir W. Herschel's se ond measure in 1802 , giving for the angle $62^{\circ} 59^{\prime}$, or less than $3^{\circ}$ in advance of his measure I78 I, August I7. when the companion was first detected. The measure of I 802 was registered s.p. and "corrected by a subsequent observation to n.f.," as Sir John Herschel states in Memoirs R.A.S. vol.v. p. 46 ; but it is now pretty evident, from a projection of all the measures to 1875 , that the quadrant was correctly registered s.p., and consequently the angle for $1802 \cdot 246$ should be $207^{\circ} I^{\prime}$ according to our present method of reckoning. The angle calculated for this time from the above orbit is $206^{\circ} 55^{\prime}$, and this close agreement must be taken as very satisfactory evidence that Dr. Doberck has given us something like the true orbit, notwithstanding the difficulty of the case. It had been surmised that $\mathrm{Sir}$ W. Herschel's measures were to be increased $180^{\circ}$, Struve, in 1819 , obtaining an angle of $228^{\circ}$, and Herschel and South, in I821, $229^{\circ}$, but the position of the companion on the preceding side of the principal star, instead of the following side where it had been seen in $I 78 r$, was accounted for both by Sir John Herschel in his "Micrometrical Measures of 364 Double Stars," and by Struve in "Mensuræ Micrometricæ," by supposing motion in an orbit passing nearly through the eye of the observer, with the longer axis of the ellipse but slightly inclined to the meridian. Dr. Doberck finds an inclination to the tangent plane of the heavens, of $70^{\circ}$. Calculating from his elements, the following appear to have been the angles and distances from 1785 to 1800 :-

\begin{tabular}{|c|c|c|c|c|c|}
\hline $1785^{\circ} \mathrm{O}$ & $\ldots$ & Position & $74^{\circ} \circ$ & $\ldots$ & Distance \\
\hline $90^{\circ} 0$ & $\cdots$ & $"$ & $98 \cdot 3$ & $\cdots$ & $"$ \\
\hline 925 & $\cdots$ & " & 1320 & $\cdots$ & $"$ \\
\hline I $795^{\circ} \mathrm{O}$ & $\cdots$ & " & 1627 & $\ldots$ & $"$ \\
\hline $1800^{\circ} 0$ & $\ldots$ & ", & $199^{\circ} 0$ & $\ldots$ & ., \\
\hline
\end{tabular}

The calculated distance for epoch of Sir W. Herschel's measure in $178 \mathrm{I}$ is $\mathrm{O}^{\prime \prime} \cdot 89$, and for that of $1802, \mathrm{I}^{\prime \prime} \cdot 05$; the observed distances being only by estimation in diameters of the companion, giving " $\frac{1}{2}$ or $\frac{3}{4}$ diameter" of smaller star in 1781 , and "barely $\frac{1}{2}$ diameter" in 1802, with power 460 in both years, are perhaps sufficiently well represented, though very admissible correction to one or two of the elements may diminish the distance in 1802 or increase that in $178 \mathrm{I}$.

For comparison with future measures we have from Dr. Doberck's orbit-

\begin{tabular}{|c|c|c|c|c|c|}
\hline $1876^{\circ} 0$ & & Position & $241^{\circ} \cdot 45$ & $\ldots$ & Distance \\
\hline 78.0 & ... & $"$ & $241 \cdot 71$ & $\cdots$ & $\Rightarrow$ \\
\hline 80.0 & $\ldots$ & " & $241 \cdot 97$ & $\cdots$ &, \\
\hline
\end{tabular}

The Minor Planets.-In No. 35 of the Circulars of the Berliner Astronomisches Fahrbuch, Prof. Tietjen. notifies an arrangement which has been entered into by the Observatories of Leipsic, Leyden, Lund, Pola, and Vienna, for the more systematic and regular observation of the small planets. These Observatories have agreed to report to the editor of the 7 ahrbuch, every fortnight, the names or numbers of the planets which have been observed, with the dates of observation and the limits within which the planets whose positions are more uncertain have been sought. These communications will be so timed that they may arrive at Berlin on the Ist and 15 th of the month, and will be there arranged, printed, and circulated. An invitation is extended to those Observatories where the small planets are occasionally, though not regularly, observed, to join in the proposed scheme. In the same manner the state of calculation as regards the various members of this group will be made known. TheMilan Observatory has already engaged itself to calcula tion for No, I 5 I.

Mr. Daniel Kirkwood, of Bloomington, Indiana, writes with reference to the resemblance which exists between the elements of certain minor planets, instancing as the most striking case that of No. 54, Alexandra, and No. I4I, Lumen. An inadvertent application of the angle usually designated $\omega$ (or the distance of perihelion from node) in the wrong direction, renders the similarity between the orbits of these planets somewhat less striking than in Mr. Kirkwood's communication, but there is nevertheless considerable resemblance, as the following figures will indicate :-

\begin{tabular}{|c|c|c|c|c|}
\hline & & Alexandra. & & Lumen. \\
\hline Perihelion ... & ... & $294^{\circ} \times 6^{\prime}$. & & $34 \mathrm{I}^{\circ} 32^{\prime}$ \\
\hline & $\ldots$ & $313^{\circ} 49^{\prime}$ & $\cdots$ & $318^{\circ} 59^{\prime}$ \\
\hline Inclination $\ldots$ & $\ldots$ & $1 \mathbf{I}^{\circ} 47^{\prime}$ & $\ldots$ & II $I^{\circ} 33^{\prime}$ \\
\hline Excentricity... & $\ldots$ & 0.1987 & $\ldots$ & 0.2233 \\
\hline Mean distance & $\ldots$ & 27093 & $\ldots$ & $2 \cdot 7095$ \\
\hline Period $\ldots$ & $\ldots$ & 1628.9 days. & $\ldots$ & 162900 \\
\hline
\end{tabular}

THE ZODIACAL LIGHT.-Those who are interested in the observation of this phenomenon will do well to be on the alert during dark evenings in the winter months. The most conspicuous exhibitions of the light in this country during the last few years have occurred in the month of January, the long standing recommendation to 
expect the most notable displays in the evenings about the vernal equinox having thus been by no means justified in the result. The light was perceptible for a short time last Sunday evening, without any yellowish tinge, and the position of axis somewhat doubtful from the indifferent state of the sky. Prof. Heis's observations in December from $185 \mathrm{I}$ to 1870 , place the mean position of the apex on the equator in R.A. $349^{\circ}$, or with about $82^{\circ}$ elongation from the sun: this refers to the eastern arm of the phenomenon.

\section{THE RATNFALL}

$\mathrm{T}$ $\mathrm{HE}$ extraordinary rainfall of the past year will make I 875 memorable in the annals of meteorology. With scarcely an exception every part of Great Britain has suffered from a plague of rain; from the Continent and from North America there come the same tidings of incessant rain and vast inundations. Even in a country so far distant as China we hear of unprecedented rains. The following statistics concerning a rainfall that occurred in China between last August 3 Ist and September ist will be read with astonishment. Our information is derived from the bulletins of the Meteorological Observatory of the Fathers of the Society of Jesus at Sikawei, on whose accuracy of observation we may doubtless depend. The readings show that between four and seven o'clock in the morning of September Ist the mean rainfall per hour was 32.7 millimetres, which makes the astonishing rate of $\mathbf{r} 287$ inch for each of those three hours. Well may the compiler remark, "We think there are few examples of such a figure, except in the case of waterspouts."

The total quantity that fell in the garden of the Jesuit Observatory during the twenty-four hours that elapsed between four o'clock on Tuesday, 3ist August, and the same hour in the afternoon of Wednesday, Ist September, was 2 I 8 millimetres, or no less than 8.59 inches for the rainfall of a singie day! After this the records of rainfall in Great Britain look insignificant. Nevertheless the fall has far exceeded the ordinary statistics. At Balbriggan, a town a few miles north of Dublin, the rainfall from 9 A.M. on the $13^{\text {th }}$ inst. to 9 A.M. on the $14^{\text {th }}$ inst. was two inches. This is the greatest fall in twenty-four hours which occurred in that town for the last ten years.

It is important to obtain statistics from the southern hemisphere. It is probable a vast drought must somewhere compensate for the floods of water poured over a large part of the northern hemisphere.

\section{THE WORK OF THE CHALLENGER*}

TH

IS report is dated from Hilo Hawaii, August I8, and describes the cruise of the Challenger from Yokohama to the Sandwich Islands. The Challenger left Yokohama on the 16 th of June, and ran an easterly course between the parallels of $35^{\circ}$ and $40^{\circ}$ north latitude, as far as the meridians of $155^{\circ}$ east. She then turned nearly directly southwards and reached Honolulu on the 27th of July. Twenty-four observing stations were established, at each of which most of the desired observations were made.

On the I7th of June, Prof. Thomson's Report goes on, we sounded in 1,875 fathoms with a bottom of bluish-grey clay and a bottom-temperature of $\mathrm{I}^{\circ} 7 \mathrm{C}$., forty miles to the south-east of No Sima Lighthouse. The trawl was put over, and it brought up a large quantity of the bottom, which showed the clay was in a peculiar concretionary state, run together into coherent lumps, which were bored in all directions by an Anrelid of the Aphroditacean group. In many cases the Annelids

* Abstract of " Report to the Hydrographer of the Admiralty on the Cruise of H.iv.S. Challenger from June to August 1875 , "by Prof. Wyville React at the Royal Society Noy. I8. were still in the burrows. Among the clay there were large lumps of grey pumice. The hyoid zoophytes were represented by a very remarkable species, apparently referable to the genus Monocaulon of Sars, a Corymorpha-like solitary polyp with adelocodonic gonophores; but instead of being of the proportions usual in its group, the stem in one of our specimens measured upwards of seven feet in height, while the polyp-head was nine inches in diameter across the proximal row of tentacles. We afterwards got another fine example of the same species at a depth of 2,900 fathoms (Station 248). The temperature of the surface of the sea stood during the day at nearly $23^{\circ} \mathrm{C}$., considerably above the temperature of the air ; and a serial sounding gave the isotherm of $10^{\circ} \mathrm{C}$. at a depth of little more than 200 fathoms. We were therefore evidently under the thermic influence of the Japan current, which was found by observation to be running in an easterly direction at a rate of $1 \frac{1}{2}$ knots an hour. The thermometers registered a uniform temperature of $1^{\circ} .7 \mathrm{C}$. from a depth of 1,000 fathoms to the bottom. About twenty Albatrosses of a nearly uniform brown plumage with whitish heads, probably the young of the common North-Pacific species in their second year's plumage, followed the ship.

On the following day there was a stiff breeze from the southward, and with a heavy sea. We sounded, however, successfully in 3,950 fathoms, our deepest sounding in the North Pacific position by dead reckoning lat. $34^{\circ} 43^{\prime} \mathrm{N}$., long. I $44^{\circ} 2^{\prime}$ E., with a bottom of "red clay." The high surface-temperature continued to be maintained; and the position of the isotherm of $10^{\circ} \mathrm{C}$., at station 239 at a depth of nearly 300 fathoms, indicates that up to this point, at all events, there was no diminution in the influence of the "Kuro-Siwa."

On the 2 Ist the temperature-observations gave a singular result. The surface-temperature had fallen to $18^{\circ} .2 \mathrm{C}$, and the belt of water above $10^{\circ} \mathrm{C}$. was reduced in depth to considerably below too fathoms, while all the isotherms, at all events to a depth of 400 fathoms, rose in proportion. There seems to be little doubt, from a comparison of the American temperature-results with our own, that this sudden diminution of temperature is due to a cold surface-flow from the Sea of Okhotsk, probably through Pico Channel or Vries Strait. Very likely its effect may not be found to be constant; and at this season it possibly attains its maximum from the melting of the snow over the vast region drained by the Amoor and the Udi and Siberian rivers with a southern outflow.

On the 26 th of June we sounded in 2,800 fathoms. Several forms were met with which apparently do not occur on the surface, particularly a number of species of a group which is so far as we know entirely undescribed. It seems to be intermediate between the Radiolarians and the Foraminiferas, resembling the former in the condition and appearance of the sarcode and in the siliceous composition of the test, and the latter in external form. The broken tests of these organisms are extremely abundant in the "red clay" soundings; a sufficient number of observations has not yet been made to enable us to say with certainty what is their bathymetrical distribution. From a zoological point of view the haul of the 28 th was remarkably successful ; there were one or two fishes, a Scalpellum, a number of annelids, particularly a prominent aphroditacean; Echinoderms of the genera Pourtalesia, Archaster, Brisinga, and Antedon; a fine species of Comularia, several examples of Fungia sym. metrica, and some Actinia. The general distribution of temperature remained much the same, the isotherm of $10^{\circ} \mathrm{C}$, retaining its position near the 200 -fathom line.

We trawled on the 2nd of July in 2,050 fathoms with a bottom of light brownish ooze with many Globigerinashells. The bag brought up a number of lumps of pumice and among them a very characteristic assemblage of deep-sea animals, the most interesting an undescribed 